\title{
Acrokeratosis verruciformis of Hopf
}

INSERM

\section{Source}

INSERM. (1999). Orphanet: an online rare disease and orphan drug data base.

Acrokeratosis verruciformis of Hopf. ORPHA:79151

A rare, genetic, acrokeratoderma disease characterized by multiple, symmetrical, asymptomatic, skin-colored (rarely, brownish), flat-topped, wart-like papules located on the dorsal aspects of the hands and feet (occasionally found on other parts of the body, such as knees, elbows and forearms), typically associated with palmoplantar punctate keratosis and variable nail involvement (including leukonychia, thickening, ridging, long itudinal striations and splitting). Histology reveals undulating hyperkeratosis, papillomatosis, hypergranulosis, and acanthosis, creating a characteristic "church spire" appearance, with no acantholysis nor dyskeratosis associated. 